\title{
De politie in de Lage Landen en haar confron- tatie met het nazisme ${ }^{1}$
}

\author{
Rudi VAn DoorsLaer
}

Fijnaut, C., De geschiedenis van de Nederlandse politie. Een staatsinstelling in de maalstroom van de geschiedenis (Amsterdam: Boom, 2007, 1029 blz., ISBN 978908506275 2); Meershoek, G., De geschiedenis van de Nederlandse politie. De gemeentepolitie in een veranderende samenleving (Amsterdam: Boom, 2007, 546 blz., ISBN 978908506278 3); Smeets, J., De geschiedenis van de Nederlandse politie. Verdeeldheid en eenheid in het rijkspolitieapparaat (Amsterdam: Boom, 2007, 616 blz., ISBN 978908506276 9); Wal, R. van der, De geschiedenis van de Nederlandse politie. De vakorganisatie en het beroepsonderwijs (Amsterdam: Boom, 2007, 619 blz., ISBN 978908506 277 6); Fijnaut, C., De geschiedenis van de Nederlandse politie [samenvattend deel] (Amsterdam: Boom, 2007, 187 blz., ISBN 978908506274 5).

Mijn bijdrage aan dit discussiedossier heeft twee beperkingen. Ten eerste, wordt er gefocust op de Tweede Wereldoorlog en steun ik mij daarvoor exclusief op hoofdstuk 5 van de studie van Cyrille Fijnaut. Ten tweede, staat in deze reactie de vergelijking met België voorop. Deze beperkte invalshoek laat mij evenwel toe nader in te gaan op de politiegeschiedenis zowel als op de bezettingsgeschiedenis van de Lage Landen. Die hebben zoals bekend niet hetzelfde bezettingsregime gekend: een civiel bestuur in Amsterdam en een militair bestuur in Brussel. Toch bestond er grote overeenkomst in de algemene doelstelling van de bezetter in beide landen. Het handhaven van de openbare orde ter realisatie van de economische exploitatie van het bezette land stond daarbij hoog op de prioriteitenlijst. Een, zo zou achteraf blijken, kapitaal verschil school in de toevoeging: het integreren van Nederland in de nationaalsocialistische projecten van het NSDAP-regime. Dit was in België geen prioritaire, algemeen gedeelde, doelstelling van het Militaire bestuur onder leiding van generaal von Falkenhausen en zijn bestuurschef Eggert Reeder. In hoeverre, zo vroegen wij ons voor deze bespreking af, had dit verschil consequenties voor de politiegeschiedenis in beide landen? En, in hoeverre speelde de verschillende politieke en administratieve context waarin de politiediensten zich bewogen in Nederland en België een rol?

Voor een goed begrip: in beide landen zien de bezettingsautoriteiten de werking van en de controle op de politiediensten als een allerbelangrijkste zaak. In beide landen wordt de bewaring van rust en orde als een absolute voorwaarde beschouwd voor de realisatie van de politieke en economische objectieven van het Reich. Opvallend is dat het ideologische verschil tussen de beide bezettingsregimes op het terrein van de politieproblematiek bijzonder

1 Naar aanleiding van C. Fijnaut, De geschiedenis van de Nederlandse politie. Een staatsinstelling in de maalstroom van de geschiedenis (Amsterdam 2007). 
snel tot uiting komt. Reeds op 3 juni 1940 wordt in een decreet vastgelegd dat de Nederlandse politie niet valt onder het bestuurlijke gezag van de secretarissen-generaal maar onder dat van de Duitse Hogere SS- en Politieleider in Nederland (Hanns Rauter). In België blijven de politiediensten onder het gezag van de autochtone autoriteiten, in casu de secretarissen-generaal van Binnenlandse Zaken en van Justitie, de procureurs bij de parketten en de burgemeesters (die laatste zijn daarenboven, anders dan in Nederland, politiek verkozen). Daarmee is een aanzet gegeven tot soms belangrijke verschillen, soms ook weer gelijkenissen, op het vlak van de reorganisatie van de politiediensten, van de strijd om de 'ziel' van de politie en van het optreden van de diensten als hulporganen van de nazistische repressiemachine.

\section{Nazificatie in Nederland}

In Nederland vormen de oorlogsjaren, aldus Fijnaut, een 'kolossale breuk' in de geschiedenis van de politiediensten. Een vorige fundamentele herinrichting van de politie dateerde uit de Napoleontische tijd, toen een andere Europese politiestaat Nederland in zijn greep kreeg. De auteur geeft het hoofdstuk over de Tweede Wereldoorlog de titel 'nazificatie' mee, waarmee hij doelt op het proces van gelijkschakeling en van integratie van de Nederlandse politie in het nationaal-socialistische SS-politieapparaat.

\section{Rauter op bezoek bij het Politie-Opleidingsbataljon te Schalkhaar (Bron:} Marechausseemuseum, Buren)

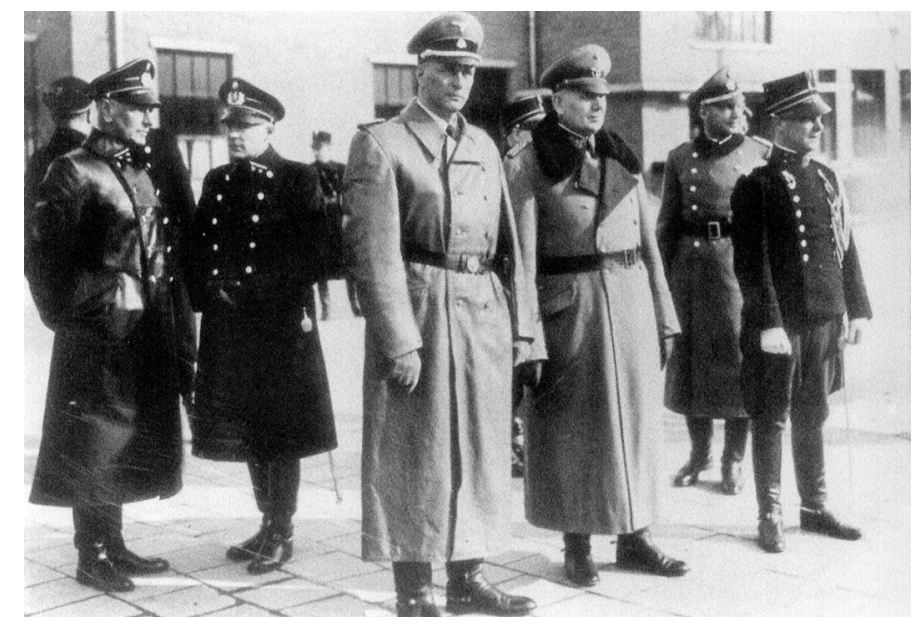

In een eerste fase, voor de Februaristaking van 1941, worden in Nederland enkele hervormingen doorgevoerd die ogenschijnlijk deels in de lijn liggen van hervormingsplannen die reeds voor de oorlog circuleerden. Er wordt een topstructuur gecreëerd bij het ministerie van Justitie, de rijkspolitiediensten (drie voor 1940) worden gefuseerd in de Marechaussee (het gemilitariseerde korps vergelijkbaar met de Belgische Rijkswacht), de gemeentepolitie in de grote steden wordt uit haar inbedding in het lokale bestuur gelicht en 
verstatelijkt en er wordt een landelijke recherche (gerechtelijke opsporingsdienst) opgericht. Het lijkt erop - maar het is slechts schijn, zo schrijft Fijnaut - dat het gefragmenteerde politiebestel daardoor uit een impasse is geraakt en tot een voor de oorlog ondenkbare eenheid is gekomen.

Maar dat alles volstaat voor Rauter en Rijkscommissaris Seys-Inquart niet. De slagkracht en inzetbaarheid van de Nederlandse politiediensten bij de februaristaking is voor hen een ontnuchterend schouwspel. Vanaf nu komen de Nederlandse verantwoordelijken er niet meer aan te pas en komt er een radicale door de bezetter gestuurde nazificering op gang die geen uitstaans meer heeft met de vooroorlogse organisatie of plannen. Er wordt nu een herstructurering doorgevoerd op het model van de door de nazi's gestuurde hervorming in Duitsland na 1933.

De reorganisatie van de politieke opsporingsdiensten in de drie grote steden wordt veralgemeend en de diensten gaan samenwerken met de Sicherheitspolizei, wat voor het Verzet desastreuze gevolgen zal hebben. De politieopleiding wordt vernieuwd en ook het politievakbondswezen wordt tot een instrument van nazificering omgesmeed. Verder wordt de positie van het openbaar ministerie verzwakt en wordt de zeggenschap over de politie volledig geconcentreerd bij de secretaris-generaal van het ministerie van Justitie. Bij dit alles worden er tussen de herfst van 1941 en het najaar van 1942 tussen 350 en 400 politiemensen weggezuiverd in de diverse korpsen. Het burgerlijke bezettingsbestuur wil het gehele machtsapparaat van de politie verzelfstandigd zien, uiteraard onder Duits gezag. Terecht merkt Fijnaut op dat al deze wijzigingen samen leiden tot een afzonderlijk politiebestuur, in wezen de belichaming van een moderne politiestaat.

Achteraf gezien lijkt de medewerking in de zomer van 1942 van de Nederlandse politie aan de arrestatie van Joden (en zigeuners!) een soort lakmoesproef voor haar loyaliteit te zijn geweest. Fijnaut geeft terecht aan dat hier de vraag naar de limiet van deze samenwerking aan de orde was. De procureurs-generaal waren politiek verdeeld en kwamen er uiteindelijk niet uit. Tijdens de oorlog werd het haarscherp duidelijk dat de politie een bijzonder delicate positie bekleedde in de maatschappij, door Fijnaut met de term 'frontlijnorganisatie' bedacht. In ieder geval luidt de conclusie van de auteur dat de nazistische aanpassing van het politiebestel de deportatie van de Joden heeft vergemakkelijkt, zoals omgekeerd de Jodendeportatie de nazificatie van de politie heeft aangescherpt.

Zonder vooruit te lopen op een globale vergelijking met België, ben ik van mening dat dit punt van bijzonder belang is. Bij de grote stedelijke korpsen werden er in Nederland speciale eenheden opgericht om de deportatie van de Joden te coördineren. Het transitkamp van Westerbork werd bewaakt door de Marechaussee. De politieke opsporingsdienst van Amsterdam voerde samen met de Sicherheitspolizei straatrazzia's uit. In september en oktober 1942 werden in Amsterdam en Rotterdam duizenden politieambtenaren belast met het arresteren, verzamelen en overbrengen van Joden. Daardoor groeide ook de weerstand. In december konden de Duitse autoriteiten niet echt meer rekenen op de reguliere Nederlandse politiekorpsen. De Jodendeportatie luidde dus een kentering in. 
Vanaf de winter van 1943 bestond de leiding van de Marechaussee grotendeels uit collaborateurs die de NSB in bereidheid tot samenwerking met de SS waren voorbij gestoken. In de naoorlogse zuivering kreeg $11 \%$ van de politiemensen ontslag en werd $7 \%$ disciplinair gestraft wegens medewerking met de bezetter. Tegelijkertijd groeide einde 1942 ook het verzet in de schoot van de politie. In de zomer van 1943 bekende Rauter dat hij eigenlijk niet meer op de Nederlandse politie kon rekenen.

Het complexe beeld van politiecollaboratie, verzet en zuivering wijst erop hoezeer de oorlogsgebeurtenissen voor trauma's hebben gezorgd in de schoot van de Nederlandse politiediensten tot lang na de bevrijding.

\section{Geen nazificatie in België}

In België zien we heel wat overeenkomsten, maar al evenzeer toch ook heel wat verschillen met de Nederlandse situatie. Wat hier de kern van de zaak vormt is de applicatie van de Conventie van Den Haag uit 1907, waarin de rechten en plichten van een bezettende macht en de bestuurders van het bezette land werden vastgelegd. Het moet gezegd dat Fijnaut nalaat deze juridische context in alle duidelijkheid te schetsen, wat toch noodzakelijk is voor een goed begrip van de policing tijdens de bezetting. Duitsland, zowel als België en Nederland, ondertekenden de conventie. De bezetter droeg volgens deze conventie de verantwoordelijkheid voor het bewaren van rust en orde in het bezette land. Hij kon hiervoor een beroep doen op de autochtone ordediensten. De bezetter leende dus een deel van zijn rechten en plichten uit aan de autochtone overheden. Hierdoor ontstond de facto een zekere machtsverhouding tussen de bezetter en de autochtone overheden, die evenwel permanent in beweging was. Naar welke zijde de balans overhelde, in het bijzonder op het politionele terrein, hing af van een complex samenspel van zowel contextuele als politiek/ideologische elementen. De belangrijkste daarin waren de doelstellingen van de bezettende overheden en de positie en politieke opstelling van de autochtone machtscentra die de policing beheersten.

In België bestond, net als in Nederland, een sterke traditie van gemeentelijke autonomie die zich uitte in een sterke positie van de gemeentelijke politiekorpsen, waarop de nationale politiek weinig greep had. Daarnaast had het militaire politiekorps bij uitstek, de Rijkswacht, tijdens het interbellum sterk aan slagkracht en belang gewonnen. In 1919 was er onder de hoede van de rechterlijke macht een Gerechtelijke politie (GP) opgericht die als een keurkorps belangrijke criminele en politiek-politionele taken naar zich toetrok. Organiek ressorteerde de GP onder de bevoegdheid van de minister van Justitie, die als verantwoordelijke van de Openbare Veiligheid (waaronder de Staatsveiligheid, de Vreemdelingenpolitie en de algemene administratie van de GP ressorteerde) in de jaren 1930 dus een centrale rol speelde in de policing. Het zwakke broertje in die policing was het departement van Binnenlandse Zaken, waar de Algemene Rijkspolitie wel een coördinerende rol trachtte te spelen, maar gezien de onaantastbaarheid van de gemeentelijke autonomie en het militaire karakter van de gendarmerie nauwelijks van betekenis was. Om bijgevolg uitspraken te doen over deze policing in België is het noodzakelijk het gehele plaatje te overzien: de uitvoerende macht, met Justitie voorop, de 
magistratuur, het lokale niveau en de ambtelijk-bureaucratisch tradities van de diverse korpsen zelf.

Zowel op het vlak van de hervorming van de politiediensten als op het terrein van hun werking, dekt, wanneer in Belgie de oorlogsperiode wordt geëvalueerd, anders dan in Nederland, de term nazificatie in geen geval de lading. Het Militaire bestuur lijkt op het politionele terrein weinig bewogen te zijn door ideologische doelstellingen, maar veeleer een pragmatische aanpak voor te staan. Zo werd anders dan in Nederland niet het ministerie van Justitie het bruggenhoofd van de Duitse hervormingspogingen, maar het ministerie van Binnenlandse Zaken. De aanstelling van een nieuwe secretaris-generaal, lid van het Vlaams Nationaal Verbond en bereid tot collaboratie (Gerard Romsée), was voor het Militaire bestuur de hoeksteen van de politiehervorming. Zijn niet-benoeming op het departement van Justitie lijkt een detail, maar is het niet. Zoals aangestipt speelde het departement van Binnenlandse Zaken voor 1940 een figurantenrol in de Belgische policing. In feite legde het Militaire bestuur zich, wat de aanstelling van Romsée betreft, neer bij een weigering van de magistratuur. Ongetwijfeld speelde de nationale kwestie daarbij een rol, een element dat in Nederland totaal afwezig was. In ieder geval lijkt dit in het begin van de bezetting te wijzen op een andere machtsverhouding tussen de bezetter en de autochtone administratie dan in Nederland. Die andere machtsverhouding speelde, zo is mijn indruk, een toenemende rol in de latere bezettingsjaren.

Er was in België, steunend op de Conventie van Den Haag, een wettelijke basis geschapen voor een samenwerking van de autochtone overheden onder de leiding van de secretarissen-generaal met de bezettingsautoriteiten. Deze wettelijke basis werd in 1940 sterk ondersteund door het algemene geloof in een definitieve Duitse overwinning en een wijd verspreide afkeer voor de democratie. Al snel werden de traditionele overheden geconfronteerd met een greep naar de macht van hoofdzakelijk Vlaams-nationalistische en rexistische collaborateurs. Dit beïnvloedde uiteraard het bestuur van het bezette land en in het bijzonder ook de politiezaken. Vooral was de leidende elite in de administratie en de magistratuur, althans tot het najaar van 1942, bereid tot een maximale interpretatie van de Conventie van Den Haag in diverse politionele en justitiële materies. Die maximale interpretatie sloeg op de uitvoering van Duitse verordeningen die geen Belgische rechtsgeldigheid bezaten of er zelfs mee in strijd waren. Ik verwijs voor deze problematiek naar de recente diepgravende studie van Nico Wouters over het plaatselijke bestuur in bezet België en naar het onderzoek in de problematiek van de houding van de overheden in de Jodenvervolging. ${ }^{2}$ Maar het effect van dat alles was minder

2 Nico Wouters, De Führerstaat. Overheid en collaboratie in België (1940-1944) (Tielt 2006); Rudi Van Doorslaer (ed.), Emmanuel Debruyne, Frank Seberechts en Nico Wouters (met medewerking van Lieve Saerens), Gewillig België. Overbeid en jodenvervolging tijdens de Tweede Wereldoorlog (Antwerpen, Amsterdam en Brussel 2007); Herman Van Goethem, 'La convention de La Haye, la collaboration administrative en Belgique et la persécution des Juifs à Anvers, 1940-1942', Cabiers d'Histoire du Temps Présent (30/60) - Bijdragen tot de Eigentijdse Geschiedenis (2006) nr. 17, 117-198. 
verregaand en veralgemeend, zo lijkt het mij, dan in Nederland.

Ook in België werd gesleuteld aan de politieorganisatie en -werking in de zin van een centralisatie, opvoering van de slagkracht, zuivering van onbetrouwbare elementen en aanstelling van collaborateurs op sleutelfuncties. In eerste instantie steunde de bezetter daarbij op het meest gedisciplineerde en efficiënte korps: de Rijkswacht. De sympathie die deze voorkeursbehandeling had kunnen opwekken, werd evenwel teniet gedaan door de integratie van uit krijgsgevangenschap vrijgelaten Duitsgezinde Vlaamse legerofficieren. Opnieuw speelde de nationale kwestie eind 1941, begin 1942 dus een rol. Een goed jaar later moest het Militaire bestuur vaststellen dat de Rijkswachthervorming was mislukt en het de patriottische reflexen niet had kunnen breken. Op het vlak van de gemeentepolitie werd via de Algemene Rijkspolitie op Binnenlandse Zaken gesleuteld aan de centralisering van de opleiding en werving. Door de vorming van zogenaamde Grote agglomeraties in zeven grote steden werd de mogelijkheid gecreëerd om Nieuwe Orde-aanhangers te benoemen. Aan een verstaatsing van de gemeentepolitie durfde het Militaire bestuur zich echter niet te wagen. Er waren de grondwettelijke bezwaren, maar al evenzeer de vrees voor een paard van Troje-effect.

Wat de werking van de politiediensten betreft hebben er drie onderling verbonden problemen de bezettingsgeschiedenis beheerst: de toepassing van de Duitse verordeningen, de autonomie van het gerechtelijke onderzoek en de politieke kwesties van anticommunisme en strijd tegen het verzet. Vele van deze materies zijn met betrekking tot België nog nauwelijks op een systematische manier onderzocht. Enkel de Jodenvervolging vormt hierop een uitzondering. Wanneer ik Fijnauts politiegeschiedenis tijdens de bezetting lees, valt het mij op dat ook bij hem een duidelijk en volledig overzicht van deze materies ontbreekt. Hier en daar zijn er aanwijzingen over activiteiten van de opsporingsdiensten, zowel met betrekking tot strijd tegen het Verzet als tegen Joodse onderduikers. Maar werden bijvoorbeeld gegevens over Nederlandse communisten doorgegeven aan de Sicherheitspolizei? En speelde de nieuwe context na de aanval van Duitsland op de Sovjet-Unie überhaupt een rol in de houding van de politieambtenaren? Wat België betreft zijn daarover wel enkele aanwijzingen bekend, maar een vergelijking met Nederland kan ik op basis van de synthese van Fijnaut niet maken. Eind 1942, toen de politieke situatie in bezet België als gevolg van de invoering van de verplichte tewerkstelling in Duitsland drastisch kantelde in het nadeel van de bezetter, trachtte de bezetter, via secretaris-generaal Romsée, een Burgerlijke Staatspolitie op te richten om ook van Belgische zijde efficiënt op te treden tegen het 'terrorisme' (lees de activiteiten van het gewapende verzet). Opnieuw botsten hij en de bezetter op de onwil van de meerderheid van zijn collega's en van de gerechtelijke macht. In die periode werd ook de maximale interpretatie van de Conventie van Den Haag teruggeschroefd en konden geen verordeningen meer worden uitgevoerd door de veiligheidsdiensten die geen wettelijke Belgische basis bezaten. De machtsbalans waarover eerder sprake sloeg vanaf die periode meer en meer door in het nadeel van de bezetter. Wel waren ondertussen, in de zomer van 1942, de wegvoeringen van de Joden reeds massaal doorgevoerd. Dit had in Antwerpen, dat vaak lijkt aan te schurken tegen het Nederlandse model, geleid 
tot verregaande medewerking van de plaatselijke politie. Uitleggen waarom dat in Brussel niet gebeurde zou ons hier te ver leiden, maar het staat vast dat ook op dit punt niet alleen nationale maar ook internationale vergelijking uitermate verhelderend zou kunnen zijn.

Uit dit alles komt te voorschijn dat in België de politiediensten slechts een reus op lemen voeten bleken te zijn zonder de medewerking van de magistratuur. Is dit een Belgische specificiteit en het gevolg van de machtspositie van de rechterlijke macht (als gevolg van de 'verzetsrol' van de magistratuur tijdens de Eerste Wereldoorlog)? Opnieuw kan slechts internationale vergelijking op deze vraag een antwoord formuleren. Uit de studie van deze crisisperiode (die de bezetting toch is geweest) komt in ieder geval naar voren dat de geschiedenis van de politie en de policing slechts kan bestudeerd worden wanneer alle machtscomponenten in hun interactie worden belicht. Geïsoleerde monografieën over een stedelijk politiekorps, of zelfs over de Rijkswacht, roepen vaak meer vragen op dan ze beantwoorden. Maar vooral de rechterlijke macht mag in geen geval ontbreken. $\mathrm{Nu}$ is de Nederlandse magistratuur in de studie van Fijnaut slechts sporadisch en via kleine hints aanwezig. In het bijzonder werd het mij in het verhaal van de auteur niet duidelijk hoe het kon gebeuren dat de magistratuur op een dergelijke manier de diverse Nederlandse politiediensten buiten de wettelijke paden liet treden.

\section{Uitzonderlijke betekenis van de bezetting}

Ter samenvatting van deze tot de bezetting beperkte kijk op de monumentale studie van Cyrille Fijnaut, onze grote bewondering voor zijn breed overzicht, maar anderzijds toch ook enkele vragen. Vooreerst is er de onduidelijke juridische context waarin de politie diende te functioneren en de zo goed als afwezigheid van de magistratuur in het verhaal. Ook de politieke betekenis van de rol van bepaalde korpsen in de bestrijding van het Verzet en de illegale communisten in het bijzonder, lijkt mij onvoldoende belicht.

Wat de bezettingsgeschiedenis betreft, is de politiegeschiedenis mijns inziens van uitzonderlijke betekenis. Uit de studie van Fijnaut en uit mijn lectuur van de diverse deelstudies in verband met België kan worden afgeleid dat de graad van samenwerking met de bezetter en de duur ervan in Nederland groter was dan in België. Op de vraag of dit dient te worden toegeschreven aan het andere bezettingsregime, dan wel aan de algemene bestuurlijke context of aan de geschiedenis en structuur van de politiediensten zelf, zou ik in het bestek van deze bespreking geen antwoord durven te geven. In dit verband ben ik een grote pleitbezorger van comparatief onderzoek, nationaal en vooral internationaal. Zowel met betrekking tot de Lage Landen als met betrekking tot Frankrijk, die toch beiden prat gaan op een liberaal-democratische traditie, lijkt het mij ook vanuit maatschappelijk perspectief niet van enig belang ontbloot om na te gaan hoe de politiediensten - met hun mensen en structuren hebben gereageerd op deze pijnlijke confrontatie met de dictatuur van de nazibezetting. 
Debryune, Frank Seberechts en Nico Wouters (m.m.v. Lieven Saerens), Gewillig België. Overheid en Jodenvervolging tijdens de Tweede Wereldoorlog (Antwerpen, Amsterdam en Brussel 2007).

Summary

Rudi Van Doorslaer, The Police Force in the Low Countries and its Confrontation with Nazism

In responce to the publication De geschiedenis van de Nederlandse politie by Cyrille Fijnaut, this contribution examines the World War II period and thereby shifts the focus to a comparison between the Netherlands and Belgium. The initial conclusion is that the level of cooperation with the occupational forces was greater in the Netherlands than in Belgium. Yet, despite the monumental nature of Fijnaut's study, a lot of grey areas and unresolved questions remain concerning both countries. In our view, international comparative research is the correct path to follow in order to make progress on this important theme about the history of the German Occupation and the police force. Its importance is partly supported by the social relevance of this unique confrontation of police services in liberal-democratic countries with a dictatorial system of government. 


\title{
Twee eeuwen politiebestel en veranderend recht
}

\author{
CORJO JANSEN
}

\section{Inleidende beschouwingen}

Cyrille Fijnaut, hoogleraar vergelijkend en internationaal strafrecht aan de Universiteit van Tilburg, heeft een knap boek geschreven, dat bovendien op prachtige wijze is vorm- en uitgegeven. ${ }^{1}$ Hij is bij uitstek de autoriteit op het gebied van de geschiedenis van de politie. Weinige wetenschappers zullen bij de aanvang van hun onderzoek een zo degelijke kennis van hun onderwerp hebben gehad als Fijnaut. En niemand anders dan hij had binnen de betrekkelijk korte tijd van zeven jaren een dergelijke imposante (politieke) geschiedenis van de Nederlandse politie in de negentiende en twintigste eeuw met deze diepgang kunnen voltooien. Een recensent past dus bescheidenheid, zeker als hij zich nog nooit in de discussie over de politie in Nederland heeft gemengd en evenmin ooit de natuurlijke aandrang daartoe heeft gevoeld. Toen ik me aan de lezing van het kloeke boek van Fijnaut zette, drong zich één bezwaar aan me op: het werk is wel heel omvangrijk. Het beslaat een kleine 1000 pagina's leesstof. De auteur lijkt op de pagina's 35-36 zelfs nog te willen betogen dat deze geschiedenis gelet op de tijdspanne van twee eeuwen die hij moest beschrijven en de complexiteit van de politieorganisatie 'alarmingly short' is. Smaken verschillen wellicht, hoewel mij het gevoel bekroop dat de auteur het soms allemaal wat korter had kunnen zeggen. Een ander - uiterlijk - bezwaar is de titel van het boek. Die vind ik door het gebruik van twee keer het woord 'geschiedenis' weinig fraai.

Fijnaut geeft in zijn algemene inleiding aan dat is gekozen voor een institutionele invalshoek bij de organisatie van het onderzoek voor deze geschiedenis (21 en volgende). De inbedding van het politieapparaat in het staatsbestel heeft naar zijn inzicht in de politieke discussies over de politie altijd voorop gestaan: welke bestuurlijke, justitiële of militaire autoriteit heeft er onder welke omstandigheden en op welke manieren iets over te zeggen gehad? De politie heeft immers, zo schrijft Fijnaut terecht, in vredestijd in beginsel het monopolie op de daadwerkelijke uitoefening van geweld. $\mathrm{Zij}$ is volgens hem in Nederland een staatsinstelling pur sang. Hij spreekt ten aanzien van de politie zelfs van een ongeschreven staatsrechtelijke regel (waarvan het ontstaan in 1850 is te dateren) dat de inrichting van de politie zo cruciaal is voor een goede werking van de Nederlandse staat dat alleen het parlement kan bepalen hoe deze instelling moet worden georganiseerd. ${ }^{2}$

1 C. Fijnaut, De geschiedenis van de Nederlandse politie. Een staatsinstelling in de maalstroom van de geschiedenis (Amsterdam 2007).

2 C. Fijnaut, 'Zwaartepunten in de geschiedenis van de Nederlandse politie', in: C. Fijnaut (ed.), 200 Jaar politiegeschiedenis. Toespraken bij de presentatie van De geschiedenis van de Nederlandse politie (Amsterdam 2007) 13. 